\title{
Common-Sense-Based Theoretical Explanation for an Empirical Formula Estimating Road Quality
}

\author{
Edgar Daniel Rodriguez Velasquez \\ The University of Texas at El Paso, edrodriguezvelasquez@miners.utep.edu \\ Vladik Kreinovich \\ The University of Texas at El Paso, vladik@utep.edu
}

Follow this and additional works at: https://scholarworks.utep.edu/cs_techrep

Part of the Applied Mathematics Commons

Comments:

Technical Report: UTEP-CS-20-64

\section{Recommended Citation}

Rodriguez Velasquez, Edgar Daniel and Kreinovich, Vladik, "Common-Sense-Based Theoretical Explanation for an Empirical Formula Estimating Road Quality" (2020). Departmental Technical Reports (CS). 1473.

https://scholarworks.utep.edu/cs_techrep/1473

This Article is brought to you for free and open access by the Computer Science at ScholarWorks@UTEP. It has been accepted for inclusion in Departmental Technical Reports (CS) by an authorized administrator of ScholarWorks@UTEP. For more information, please contact Iweber@utep.edu. 


\title{
Common-Sense-Based Theoretical Explanation for an Empirical Formula Estimating Road Quality
}

\author{
Edgar Daniel Rodriguez Velasquez ${ }^{1,2}$ and Vladik Kreinovich ${ }^{3}$ \\ ${ }^{1}$ Department of Civil Engineering \\ Universidad de Piura in Peru (UDEP) \\ Av. Ramón Mugica 131, Piura, Peru \\ edgar.rodriguez@udep.pe \\ ${ }^{2}$ Department of Civil Engineering \\ ${ }^{3}$ Department of Computer Science \\ University of Texas at El Paso, 500 W. University \\ El Paso, TX 79968, USA \\ edrodriguezvelasquez@miners.utep.edu \\ vladik@utep.edu
}

\begin{abstract}
The quality of a road is usually gauged by a group of trained raters; the resulting numerical value is known as the Present Serviceability Index (PSI). There are, however, two problems with this approach. First, while it is practical to use trained raters to gauge the quality of major highways, there are also numerous not-so-major roads, and there is not enough trained raters to gauge the quality of all of them. Second, even for skilled raters, their estimates are somewhat subjective: different groups of raters may estimate the quality of the same road segment somewhat differently. Because of these two problems, it is desirable to be able to estimate PSI based on objective measurable characteristics. There exists a formula for such estimation recommended by the current standards. Its limitation is that this formula is purely empirical. In this paper, we provide a common-sense-based theoretical explanation for this formula.
\end{abstract}

\section{Formulation of the Problem}

How the quality of a road is gauged. To quality of a road is gauged by the Present Serviceability Index (PSI). This index is estimated by a group of skilled raters who evaluate the quality of the road while driving. This index ranges from 0 to 5 : 
- values from 4 to 5 indicate very good quality;

- values from 3 to 4 indicate good quality;

- values from 2 to 3 indicate fair quality;

- values from 1 to 2 indicate poor quality;

- values from 0 to 1 indicate very poor quality.

For major highways, right after construction, PSI is about 4.2. If the PSI goes below 2.5 , this means that the road is in need to maintenance.

Need for estimating PSI based on measurable characteristics. There are two problems with this usual approach.

The first problem is related to the fact that the standard way of finding PSI requires the use of skilled raters. The problem is the number of skilled raters is limited. The raters are used to gauge the quality of major highways. However, there are also plenty of not-so-major roads whose quality needs to be regularly evaluated, to see whether they need maintenance. There are simply not enough skilled raters to test all the roads. So, it is desirable to be able to estimate the quality of a road by using some measurable characteristics that would not require the use of skilled experts.

The second problem is the subjectivity of the estimates. Different groups of experts produce somewhat different estimates. It is desirable to have a more objective characteristic of the road quality.

How PSI is estimated now. The current guide [1] provides the following empirical formula for estimating PSI:

$$
\mathrm{PSI}=5.03-1.91 \cdot \log _{10}(1+\mathrm{SV})-1.38 \cdot \overline{\mathrm{RD}}^{2}-0.01 \cdot(\mathrm{C}+\mathrm{P})^{1 / 2},
$$

where:

- $\mathrm{SV}$ is slope variance, i.e., the average square deviation of the local slope $y_{i}$ from its mean value $\bar{y}$, i.e., the value

$$
\mathrm{SV}=\frac{1}{n} \cdot \sum_{i=1}^{n}\left(y_{i}-\bar{y}\right)^{2}, \text { where } \bar{y}=\frac{1}{n} \cdot \sum_{i=1}^{n} y_{i} ;
$$

the slopes are usually measured every 6 inches;

- $\overline{\mathrm{RD}}$ is the average rut depth in inches;

- $\mathrm{C}+\mathrm{P}$ is the total area of cracking and patching per 1000 square feet.

Remaining problem. The main problem is that the current formula (1) is purely empirical. The experiments that led to this formula are described in [3], and the equipment use in these experiments is described in [2].

To make this formula more convincing, it is desirable to provide some theoretical justification for this formula. This is what we do in this paper: we provide a simple common-sense-based explanation for all three terms in the empirical formula (1). 


\section{Our Explanation of the Empirical Formula}

Explanation for the variance term. The slope variance is usually much larger than 1. So, for all practical purposes, we can replace the slope variance term in the formula (1) with the simplified expression

$$
1.91 \cdot \log _{10}(\mathrm{SV})
$$

In the formula (1), the value 1 was added to SV for purely theoretical reasons - not effecting the formula's practical use - namely, to make sure that for the idealized perfect road, with $\mathrm{SV}=0$, we will get PSI equal to 5 , and not to the meaningless infinity.

In the from (2), we can see that this formula is a typical example of a wellknown physiological law - Weber-Fechner law - according to which that the subjective sensation is proportional to the logarithm of the stimulus intensity; see, e.g., [4]. This fact is well known in sound perception, where the perceived intensity of the sound is usually measured in decibels - a value proportional to the logarithm of the sound's energy.

In our case, the perception of the road's non-smoothness is proportional to the logarithm of the slope variance - the objective characteristic of this nonsmoothness.

Explanation for the rut depth term. A rut is, by definition, a long deep track made by the repeated passage of the wheels of vehicles. Its width is usually about the same size as its depth, so at each section, the road area decreased by the presence of the rut is proportional to the square of its depth.

The wheel is affected by this whole area, so the effect of the road should be proportional to this area - and thus, proportional to the square of the rut depth. This is exactly what we observe in the formula (1).

Explanation for the patch-related term. The area of the patch is, roughly speaking, proportional to its linear size. Thus, the patch's linear size is proportional to the square root of the patch area.

When a vehicle passes through a patch, it is only affected by the part of the patch that is under the wheels. The area of this part is proportional to the linear size of the patch. Thus, the effect of the patch should be proportional to the linear size of this patch - hence, to the square root of the patch area. This is exactly what we observe in the empirical formula (1).

Conclusion. So, all three terms in the formula (1) are now explained.

\section{Acknowledgments}

This work was supported in part by the National Science Foundation grants 1623190 (A Model of Change for Preparing a New Generation for Professional Practice in Computer Science) and HRD-1242122 (Cyber-ShARE Center of Excellence). 


\section{References}

[1] American Association of State Highway Officials AASHTO, AASHTO Guide for Design of Pavement Structures, AASHTO, Washington, DC, 1993.

[2] W. N. Carey, H. C. Huckins, and R. C. Leathers, "Slope variance as a measure of roughness and the CHLOE Profilometer", Proceedings of the Highway Research Board Conference on the AASHO Road Test, St. Louis, Missouri, May 16-18, 1962.

[3] Highway Research Board. The AASHO Road Test, Report 7, Summary Report, Special Report 61G, National Academy of Sciences, National Research Council, Washington, DC, 1962.

[4] E. R. Kandel, T. M. Jessell, J. H. Schwartz, S. A. Siegelbaum, and A. J. Hudspeth, Principles of Neural Science, Mc-Graw Hill, New York, 2013. 